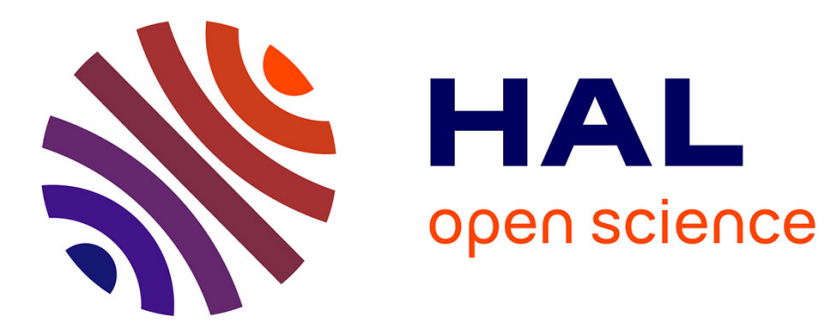

\title{
Rate constants of oxidation of unsaturated fatty esters studied by chemiluminescence
}

Emmanuel Richaud, Ludmila Audouin, Bruno Fayolle, Jacques Verdu, Lyda Matisová-Rychlá, Jozef Rychly

\section{- To cite this version:}

Emmanuel Richaud, Ludmila Audouin, Bruno Fayolle, Jacques Verdu, Lyda Matisová-Rychlá, et al.. Rate constants of oxidation of unsaturated fatty esters studied by chemiluminescence. Chemistry and Physics of Lipids, 2012, 165, pp.753-759. 10.1016/j.chemphyslip.2012.09.002 hal-01193049

\section{HAL Id: hal-01193049 \\ https://hal.science/hal-01193049}

Submitted on 4 Sep 2015

HAL is a multi-disciplinary open access archive for the deposit and dissemination of scientific research documents, whether they are published or not. The documents may come from teaching and research institutions in France or abroad, or from public or private research centers.
L'archive ouverte pluridisciplinaire HAL, est destinée au dépôt et à la diffusion de documents scientifiques de niveau recherche, publiés ou non, émanant des établissements d'enseignement et de recherche français ou étrangers, des laboratoires publics ou privés. 


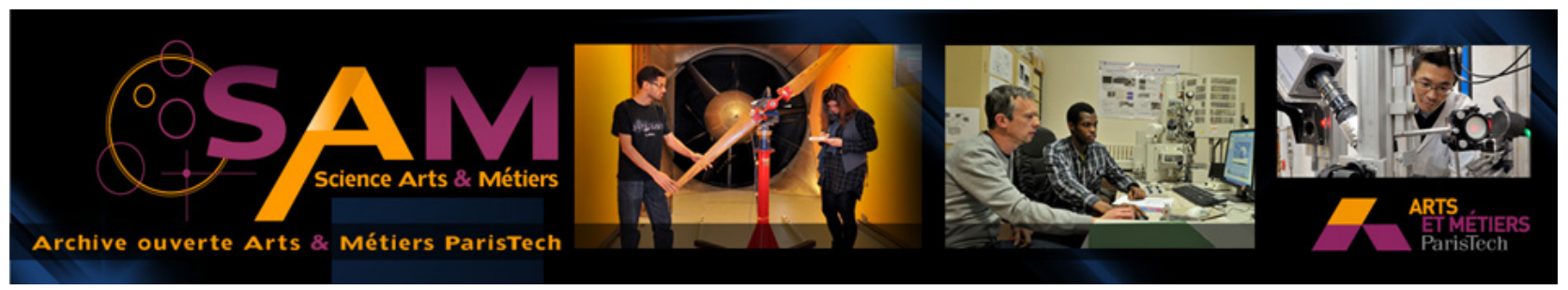

Science Arts \& Métiers (SAM)

is an open access repository that collects the work of Arts et Métiers ParisTech researchers and makes it freely available over the web where possible.

This is an author-deposited version published in: http://sam.ensam.eu

Handle ID: .http://hdl.handle.net/10985/9912

\section{To cite this version :}

Emmanuel RICHAUD, Ludmila AUDOUIN, Bruno FAYOLLE, Jacques VERDU, Lyda MATISOVÁRYCHLÁ, Jozef RYCHLY - Rate constants of oxidation of unsaturated fatty esters studied by chemiluminescence - Chemistry and Physics of Lipids - Vol. 165, p.753-759 - 2012 


\title{
Rate constants of oxidation of unsaturated fatty esters studied by chemiluminescence
}

\author{
Emmanuel Richaud a,*, Ludmila Audouin ${ }^{a}$, Bruno Fayolle ${ }^{a}$, Jacques Verdu a , \\ Lyda Matisová-Rychláb, Jozef Rychlýb \\ a Arts et Metiers ParisTech, CNRS, PIMM UMR 8006, 151 bd de l'Hôpital, 75013 Paris, France \\ b Polymer Institute, Slovak Academy of Sciences, Dúbravská cesta 11, 84236 Bratislava, Slovak Republic
}

Keywords:

Unsaturated fatty esters

Oxidation

Kinetics

Chemiluminescence

\begin{abstract}
A B S T R A C T
This study deals with oxidation kinetics of three unsaturated fatty esters: methyl oleate, methyl linoleate and methyl linolenate at temperatures ranging from 90 to $150{ }^{\circ} \mathrm{C}$. The reaction was monitored by chemiluminescence. A kinetic model was derived from a simple mechanistic scheme, in which initiation is due to hydroperoxides decomposition, whereas propagation results from the abstraction of the most labile hydrogen and termination results only from the bimolecular combination of peroxyl radicals. Analysis of induction period duration indicated that hydroperoxides mainly decompose by a bimolecular process. The model well predicts the main features of the experimental chemiluminescence curves. Kinetic parameters of the three unsaturated fatty esters were assessed from inverse method and discussed.
\end{abstract}

\section{Introduction}

The oxidation mechanism of a hydrocarbon substrate with a single reactive site under oxygen excess (i.e. no contribution of alkyl radicals $\left(\mathrm{R}^{\circ}\right)$ to termination reactions) at moderate temperature $\left(<150^{\circ} \mathrm{C}\right)$ can be depicted in a first approach by the following scheme (Tobolsky et al., 1950; Audouin et al., 1995):

$$
\begin{aligned}
& \mathrm{ROOH} \rightarrow 2 \mathrm{R}^{\circ}+\text { carbonyls }+ \text { scissions }+ \text { others }\left(k_{1 \mathrm{u}}\right) \\
& \mathrm{ROOH}+\mathrm{ROOH} \rightarrow \mathrm{R}^{\circ}+\mathrm{ROO}^{\circ}+\text { carbonyls }+\operatorname{scissions}\left(k_{1 \mathrm{~b}}\right) \\
& \mathrm{R}^{\circ}+\mathrm{O}_{2} \rightarrow \mathrm{ROO}^{\circ}\left(k_{2}\right) \\
& \mathrm{ROO}^{\circ}+\mathrm{RH} \rightarrow \mathrm{ROOH}+\mathrm{R}^{\circ}\left(k_{3}\right) \\
& \mathrm{ROO}^{\circ}+\mathrm{ROO}^{\circ} \rightarrow \text { inactive products }\left(k_{6}\right)
\end{aligned}
$$

The ratio $k_{3}^{2} / k_{6}$ expresses the intrinsic substrate oxidizability and is independent of the initiation mode (peroxide decomposition, polymer radiolysis or photolysis, etc.) (Tobolsky et al., 1950).

Initiation by uni- or bimolecular hydroperoxides (ROOH) decomposition involves in fact the formation of alkoxyl $\left(\mathrm{RO}^{\circ}\right)$ and hydroxyl $\left(\mathrm{HO}^{\circ}\right)$ radicals:

$\mathrm{ROOH} \rightarrow \mathrm{RO}^{\circ}+{ }^{\circ} \mathrm{OH}$

\footnotetext{
* Corresponding author. Tel.: +33 144246316; fax: +33 144246382

E-mail address: emmanuel.richaud@ensam.eu (E. Richaud).
}

$\mathrm{ROOH}+\mathrm{ROOH} \rightarrow \mathrm{ROO}^{\circ}+\mathrm{RO}^{\circ}+\mathrm{H}_{2} \mathrm{O}$

but $\mathrm{RO}^{\circ}$ and $\mathrm{HO}^{\circ}$ are transformed into alkyl radical by hydrogen abstraction or by rearrangement. Since both reactions are several orders of magnitude faster than $\mathrm{ROOH}$ decomposition (of rate constant $k_{1 \mathrm{u}}$ and $k_{1 \mathrm{~b}}$ ), it is licit to use the balance Eqs. (Iu) and (Ib) kinetically equivalent to the whole set of equations involving $\mathrm{ROOH}$ and $\mathrm{RO}^{\circ}$ radicals (Audouin et al., 1995). This model and some further versions were used to describe the oxidation of substrates in which it is assumed that there is only one kind of reactive site (for instance tertiary carbons in polypropylene (Richaud et al., 2006), secondary ones in polyethylene (Khelidj et al., 2006), and allylic ones in butadiene rubber (Coquillat et al., 2007)).

In the present paper, we focus on the case of methyl esters of unsaturated fatty acids (UFE). This work has the following motivations:

- UFE being the main components of biodiesels, they can be in contact with polyethylene automotive tanks. Can they accelerate the oxidation of polyethylene? The answer comes from a cooxidation model (Colin et al., 2010) which needs the knowledge of elementary rate constants including UFE ones.

- UFE oxidation is certainly close to the one of fatty acids of biological interest, involved in degenerative processes such as Parkinson or Alzheimer diseases (Spiteller, 1998; Youdim et al., 2000; Schippling et al., 2000). 
Table 1

Characteristics of the molecules under study.

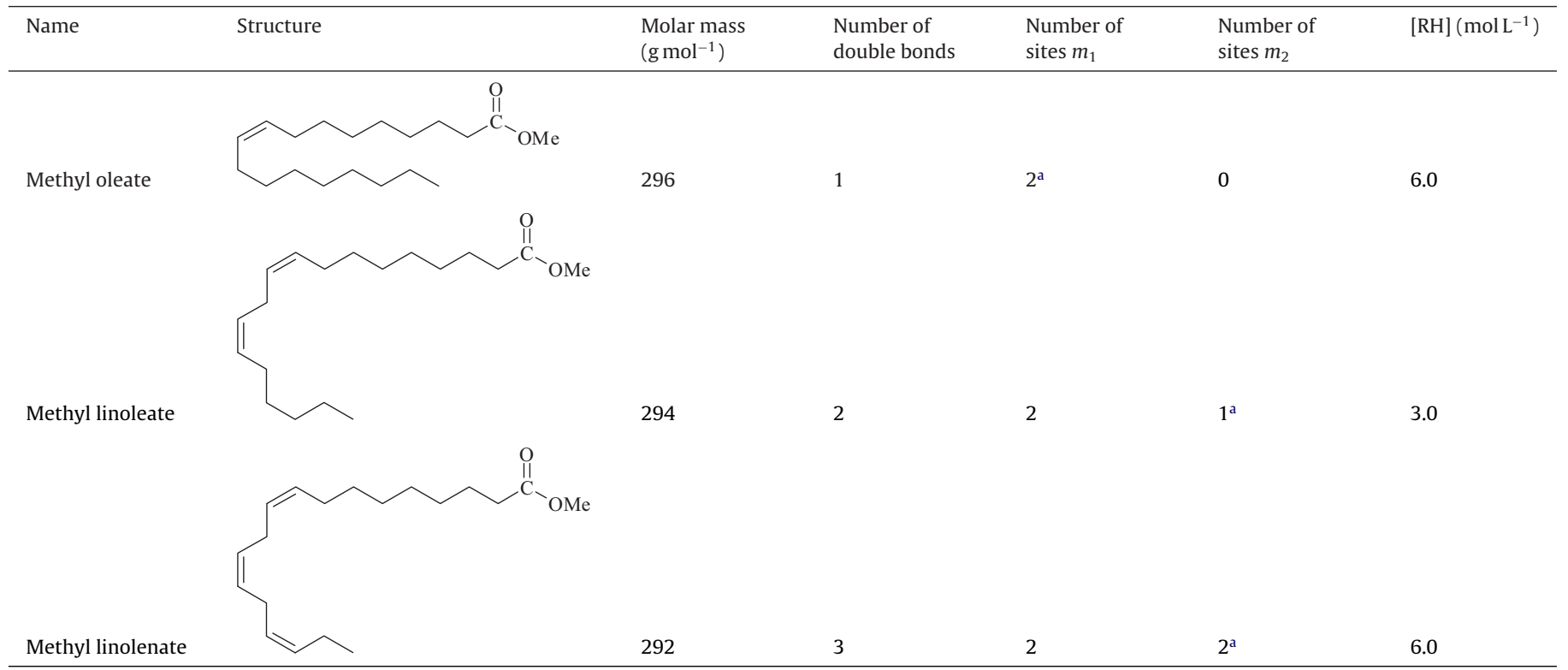

$m_{1}$, sites in $\alpha$ position of one double bond; $m_{2}$, sites in $\alpha$ position of two double bonds.

a Corresponds to the most reactive hydrogens in concentration $[R H]=\rho \times\left(m_{1}\right.$ or $\left.m_{2}\right) / M$.

- Last, it can be claimed that understanding the efficiency of antioxidants requires a modeling (Roginsky, 2010; Tavadyan et al., 2007; Zhou et al., 2004).

Oxidation of lipids and UFE has been intensively studied by oxygen absorption (Colakoglu, 2007), UV spectroscopy (Schnitzer et al., 1998; Raveh et al., 2001), NMR (Pajunen et al., 2008), MALDI-TOF (Fuchs et al., 2011) and GC chromatography (Berdeaux et al., 2012). The mechanism and the structure of intermediary and stable products as well are hence precisely known (Spiteller, 1998). Authors converge on the matter that oxidation is described by a mechanistic scheme which is common with other hydrocarbons (Colakoglu, 2007; Tükenmez et al., 1997; Cubillos et al., 2000; Roginsky, 2010; Rhayem et al., 2008). However, few studies are aimed at determining the kinetic parameters values at moderate temperature, which is a key issue to figure out more complex cases involving antioxidants. Some rate constant values are available from measures in gaseous state ( $T$ ranging from 700 to $1000 \mathrm{~K}$ ) but their extrapolation at moderate temperature seems questionable (Herbinet et al., 2008, 2010). Existing kinetic parameters values at ambient temperature are associated to very complex models, which cannot guarantee that the values were well optimized (since several sets of constants could lead to acceptable simulation of oxidation course (Tavadyan et al., 2007)). Other questions remain unsolved such as the mechanism of radicals generation since most authors use an extrinsic radical creation (radiolysis (Cubillos et al., 2000) or thermal decomposition of an initiator (Zhou et al., 2004)).

We propose here to:

- Study the UFE degradation by CL at several temperatures from 90 to $150^{\circ} \mathrm{C}$ in order to validate a simple model. The relation between the rate of oxidation linked to hydroperoxides decomposition and CL emission is widely accepted (Kron et al., 1996; Matisová-Rychlá et al., 2003; Billingham and Grigg, 2004). Its high reproducibility was illustrated in previous papers (Parejo et al., 2000; Hasegawa et al., 1997).

- Assess the rate constants of oxidation process and their activation energy from CL curves analysis (maximal steady state intensity, induction time, general shape). The sensitivity of this calculation method was illustrated elsewhere (Richaud et al., 2006) indicating that a factor 2 (unrealistically high) on induction period or maximal oxidation rate, i.e. maximal rate of $\mathrm{ROOH}$ decomposition involves an error lower than a decade in $k_{1 \mathrm{~b}}$ or $k_{6}$ for example. In other words, we will try to estimate the kinetic constants with an error lower than a 10 factor, which may constitute a first coarse grain study to orientate more precise resolution in the future.

\section{Experimental}

\subsection{Materials}

UFE are supplied by Sigma-Aldrich. Some of their characteristics are summarized in Table 1 . Ultrapure grades were chosen: methyl oleate 04754 purity $\geq 99 \%$ (Sigma), methyl linoleate L1876 purity $\geq 99 \%$ (GC) (Sigma) and methyl linolenate L2626 purity $\geq 99 \%$ (GC) (Sigma).

\subsection{Characterization by chemiluminescence}

CL experiments were performed using a Lumipol 3 apparatus designed by Polymer Institute in Slovak Academy of Science (Broska et al., 1999). UFE were placed into aluminum pans and heated under nitrogen from room temperature to the test temperature ranging from 90 to $150^{\circ} \mathrm{C}$ and then maintained at this temperature under oxygen at $0.1 \mathrm{MPa}$ pressure.

\section{Results}

CL kinetic curves for MO, ML, MLN at $90,110,140$ and $150^{\circ} \mathrm{C}$ are shown in Fig. 1. Their main characteristics are:

- an induction period (ended by the curves onset) during which oxidation auto-accelerates,

- steady state during which the oxidation rate is theoretically constant but turns in fact to be a maximum preceding a decay due to progressive substrate consumption (Richaud et al., 2007). It will be assumed in the following that at the maximum CL emission, the system is close to the theoretical steady state predicted 

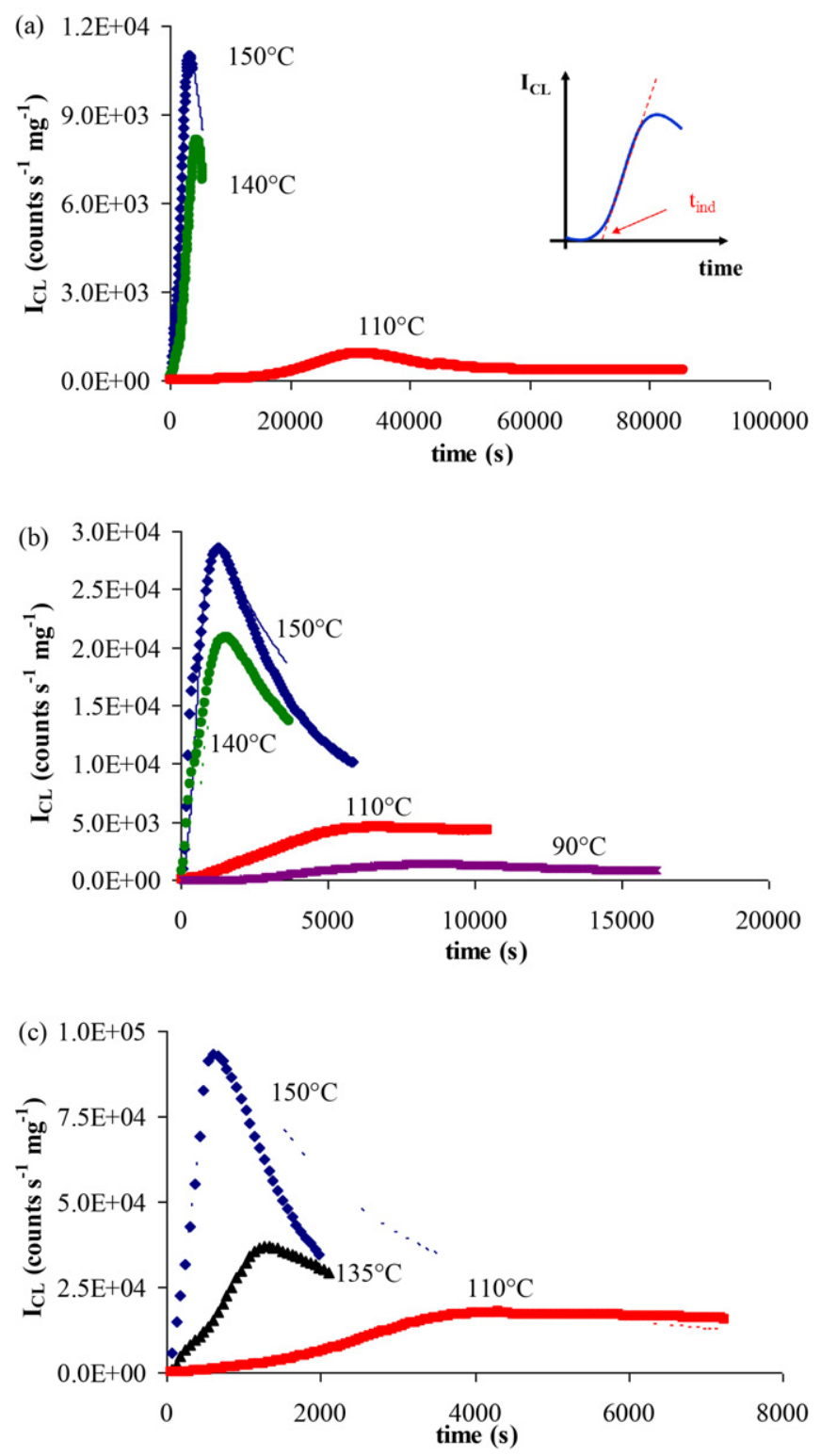

Fig. 1. Experimental traces of CL curves for methyl oleate (a), linoleate (b) and linolenate (c) at $150(\diamond), 140(\bullet), 135(\Delta), 110^{\circ} \mathrm{C}(\boldsymbol{\square})$ and $90^{\circ} \mathrm{C}\left({ }^{*}\right)$ together with their kinetic modelling (see text). Method for $t_{\mathrm{i}}$ determination is illustrated by an insert in (a).

from the classical hypothesis of constant substrate concentration (Richaud et al., 2007).

- the lower the temperature, the longer the induction period is longer and the lower the maximal CL intensity is.

These features are those predicted by the mechanistic model recalled in Section 1: the initial auto-acceleration is due to hydroperoxide accumulation increasing the initiation rate, and the steady state begins when hydroperoxides destruction and formation rates are equal.

Two quantities can be thus determined from the experimental CL kinetic curves:

- the induction time $t_{\mathrm{i}}$,

- the steady state intensity $I_{S}$ (this latter being expressed in relative units). For the curves recorded at 150 and $140^{\circ} \mathrm{C}$, we assumed that $I_{\mathrm{S}}$ was close to the maximal CL intensity (Richaud et al., 2007).

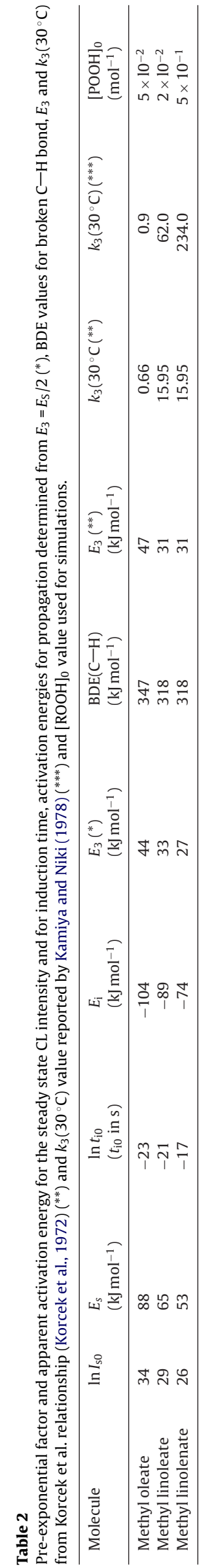


The corresponding Arrhenius parameters are given in Table 2. They call for the following comments: both quantities seem to obey Arrhenius law in the temperature interval under study, the correlation being better for $t_{\mathrm{i}}\left(R^{2}>0.99\right)$ than $I_{\mathrm{S}}\left(0.93<R^{2}<0.99\right)$. Considering the number $f$ of double bonds in the UFE, it is found that:

- At a given temperature, $I_{S}$ increases and $t_{\mathrm{i}}$ decreases when $f$ increases.

- The activation energy $E_{\mathrm{S}}$ and the pre-exponential factor $I_{\mathrm{S} 0}$ of $I_{\mathrm{S}}$ are decreasing functions of $f$.

- The activation energy and preexponential factor of $t_{\mathrm{i}}$ are indeed negative. Their absolute values are also decreasing functions of $f$.

\section{Discussion}

\subsection{On the initiation mechanism}

Several species are expected to create radicals:

(1) Allylic hydroperoxide of which the decomposition gives an alkoxyl radical $\mathrm{RO}^{\circ}$ that abstract hydrogen or rearrange by various pathways giving various kinds of alkyl radicals. It will be considered, in a first approach, that all these radicals are equireactive and that initiation maybe represented by the balance reactions ( $1 \mathrm{u}$ ) and (1b) given in the Section 1 . Let us first discuss on the relative importance of these two reactions. The analytical solution of the model in pure unimolecular $\mathrm{ROOH}$ decomposition mode leads to (Audouin et al., 1995):

$t_{\mathrm{i}}=\frac{0.386}{k_{\mathrm{u}}}$

thus:

$E_{\mathrm{u}}=-E_{\mathrm{i}}$

i.e. that activation energy for unimolecular ROOH decomposition would be equal to respectively 104.1, 88.7 and $73.6 \mathrm{~kJ} \mathrm{~mol}^{-1}$ respectively for MO, ML, and MLN. It seems that $E_{1 \mathrm{u}}$ generally is higher than $110 \mathrm{~kJ} \mathrm{~mol}^{-1}$ (Denisov and Afanas'ev, 2005a) so that the unimolecular decomposition seems not likely here.

(2) Dialkyl peroxides resulting from peroxyl addition to double bonds or from terminating bimolecular combinations of peroxyl are stable which is consistent with the fact they decompose by an unimolecular process.

In the following, we will hence only consider the bimolecular model presented in Section 1 (Ib), (2), (3) and (6) and try to estimate the corresponding kinetics parameters. The first step is link output data of this model $\left(\mathrm{R}^{\circ}, \mathrm{ROO}^{\circ}\right.$ and $\mathrm{ROOH}$ concentrations) with experimental CL intensity.

\subsection{Expression of $C L$ intensity in the bimolecular model}

Several hypotheses were proposed for explaining the origin of CL emission (Kron et al., 1996; Billingham and Grigg, 2004; AudouinJirackova and Verdu, 1987; Harada et al., 2009). Most authors converge to the hypothesis of carbonyl phosphorescence as the main source of chemiluminescence. However, the precursors of carbonyls (always $\mathrm{RO}^{\circ}$ radicals) are formed as well in initiation as in termination reactions.

$\mathrm{ROOH}+\mathrm{ROOH} \rightarrow \mathrm{RO}^{\circ}+\mathrm{ROO}^{\circ}+\mathrm{H}_{2} \mathrm{O}$

$\mathrm{ROO}^{\circ}+\mathrm{ROO}^{\circ} \rightarrow\left[\mathrm{RO}^{\circ}+\mathrm{RO}^{\circ}\right]_{\text {cage }} \rightarrow \ldots$
From the point of view of kinetic analysis, the best way would consist in expressing CL using:

$I_{\mathrm{CL}}=\varphi_{1} k_{1 \mathrm{~b}}[\mathrm{ROOH}]^{2}+\varphi_{6} k_{6}\left[\mathrm{ROO}^{\circ}\right]^{2}$

where $\varphi_{1}$ and $\varphi_{6}$ are the respective yields of $\mathrm{CL}$ in initiation and in termination.

Thermochemical arguments suggest that CL yield of initiation reaction is probably lower than the termination one but this cannot explain the CL emission at low oxygen pressures where $\mathrm{ROO}^{\circ}+\mathrm{ROO}^{\circ}$ terminations are unlikely (Achimsky et al., 1999). As mentioned in Section 1, most recent literature shows that CL emission is actually linked to ROOH decomposition (Kron et al., 1996; Matisová-Rychlá et al., 2003; Billingham and Grigg, 2004). Hence, we will consider that:

$I_{\mathrm{CL}}=\Phi k_{1 \mathrm{~b}}[\mathrm{ROOH}]^{2}$

Let us return now to the standard mechanistic scheme:

$\mathrm{ROOH}+\mathrm{ROOH} \rightarrow \mathrm{R}^{\circ}+\mathrm{ROO}^{\circ}+\Phi h \nu$

$\mathrm{R}^{\circ}+\mathrm{O}_{2} \rightarrow \mathrm{ROO}^{\circ}$

$\mathrm{ROO}^{\circ}+\mathrm{RH} \rightarrow \mathrm{ROOH}+\mathrm{R}^{\circ}$

$\mathrm{ROO}^{\circ}+\mathrm{ROO}^{\circ} \rightarrow$ inactive product $+\Phi^{\prime} h \nu$

The kinetic scheme is composed of the following equations:

$\frac{d\left[\mathrm{R}^{\circ}\right]}{d t}=k_{1 \mathrm{~b}}[\mathrm{ROOH}]^{2}-k_{2}\left[\mathrm{R}^{\circ}\right]\left[\mathrm{O}_{2}\right]+k_{3}\left[\mathrm{ROO}^{\circ}\right][\mathrm{RH}]$

$\frac{d\left[\mathrm{ROO}^{\circ}\right]}{d t}=k_{1 \mathrm{~b}}[\mathrm{ROOH}]^{2}+k_{2}\left[\mathrm{R}^{\circ}\right]\left[\mathrm{O}_{2}\right]-k_{3}\left[\mathrm{ROO}^{\circ}\right][\mathrm{RH}]-2 k_{6}\left[\mathrm{ROO}^{\circ}\right]^{2}$

$\frac{d[\mathrm{ROOH}]}{d t}=-2 k_{1 \mathrm{~b}}[\mathrm{ROOH}]^{2}+k_{3}\left[\mathrm{ROO}^{\circ}\right][\mathrm{RH}]$

At steady state termination and initiation rates are equal:

$\frac{d\left[\mathrm{R}^{\circ}\right]}{d t}+\frac{d\left[\mathrm{ROO}^{\circ}\right]}{d t}=0$

so that

$2 k_{1 \mathrm{~b}}[\mathrm{ROOH}]_{\mathrm{S}}^{2}=2 k_{6}\left[\mathrm{ROO}^{\circ}\right]_{S}^{2}$

$k_{1 \mathrm{~b}}[\mathrm{ROOH}]_{S}^{2}=k_{3}\left[\mathrm{ROO}^{\circ}\right]_{S}[\mathrm{RH}]$

By substituting $\left[\mathrm{ROO}^{\circ}\right]$ in Eqs. (9) and (10):

$[\mathrm{ROOH}]_{\mathrm{S}}=\frac{k_{3}[\mathrm{RH}]}{2 \sqrt{k_{1 \mathrm{~b}} k_{6}}}$

and

$\left(I_{\mathrm{CL}}\right)_{\mathrm{S}}=\Phi \frac{k_{3}^{2}}{2 k_{6}}[\mathrm{RH}]^{2}$

where $\Phi$ is the $\mathrm{CL}$ yield for $\mathrm{POOH}$ decomposition. The apparent activation energy of maximal CL intensity is therefore:

$E_{\mathrm{S}}=E_{\Phi}+2 E_{3}-E_{6}$

where $E_{\Phi}, E_{3}$ and $E_{6}$ are the respective activation energies of $\Phi$ $k_{3}$ and $k_{6}$. We will now try to use Eq. (13) for estimating kinetic parameters.

\subsection{Calculation of $E_{3}$ and $k_{3}(T)$ using structure-oxidizability relationships}

Most authors consider that the CL yield $\Phi$ is almost temperature independent, i.e.: $E_{\Phi}=0$. Another reasonable hypothesis is that for lipid substrates: $E_{6} \sim 0$. By assuming that $2 E_{3} \gg E_{\Phi}-E_{6}$, one obtains:

$2 E_{3} \sim E_{S}$ 
Table 3

Arrhenius parameters for bimolecular hydroperoxides decomposition.

\begin{tabular}{|c|c|c|c|c|c|c|c|c|c|}
\hline & \multicolumn{3}{|c|}{$E_{6}=0, k_{6}=10^{8} \mathrm{~L} \mathrm{~mol}^{-1} \mathrm{~s}^{-1}$} & \multicolumn{3}{|c|}{$E_{6}=30 \mathrm{~kJ} \mathrm{~mol}^{-1}, k_{6}\left(150^{\circ} \mathrm{C}\right)=10^{8} \mathrm{~L} \mathrm{~mol}^{-1} \mathrm{~s}^{-1}$} & \multicolumn{3}{|c|}{$E_{6}=0, k_{6}=10^{6} \mathrm{~L} \mathrm{~mol}^{-1} \mathrm{~s}^{-1}$} \\
\hline & $k_{1 \text { bo }}$ & $E_{1 \mathrm{~b}}$ & $k_{\mathrm{lb}}\left(150^{\circ} \mathrm{C}\right)$ & $k_{1 \text { bo }}$ & $E_{\mathrm{lb}}$ & $k_{\mathrm{lb}}\left(150^{\circ} \mathrm{C}\right)$ & $k_{1 \text { bo }}$ & $E_{1 \mathrm{~b}}$ & $k_{\mathrm{lb}}\left(150^{\circ} \mathrm{C}\right)$ \\
\hline MO & $3.37 \times 10^{10}$ & 107.4 & $1.86 \times 10^{-3}$ & $3.43 \times 10^{12}$ & 123.5 & $1.95 \times 10^{-3}$ & $5.08 \times 10^{9}$ & 110.4 & $1.19 \times 10^{-4}$ \\
\hline ML & $3.66 \times 10^{8}$ & 80.8 & $3.88 \times 10^{-2}$ & $2.99 \times 10^{10}$ & 96.1 & $4.10 \times 10^{-2}$ & $2.50 \times 10^{8}$ & 87.7 & $3.73 \times 10^{-3}$ \\
\hline MLN & $4.09 \times 10^{10}$ & 101.5 & $1.21 \times 10^{-2}$ & $1.13 \times 10^{13}$ & 123.5 & $6.42 \times 10^{-3}$ & $2.01 \times 10^{10}$ & 109.5 & $6.11 \times 10^{-4}$ \\
\hline
\end{tabular}

Eq. (14) will be tentatively validated in what follows. It gives $E_{3}$ values listed in Table 2 . They appear as a decreasing function of the number of double bonds with a more important gap between MO and ML than between ML and MLN. This is indeed linked to the difference of reactivity between $\alpha$ unsaturated and $\alpha, \alpha^{\prime}$ unsaturated methylenes:

$-\mathrm{CH}_{2}-\underset{\alpha \text { unsaturated }}{\mathrm{CH}_{2}-\mathrm{CH}}=\mathrm{CH}-\mathrm{CH}_{2}-, \quad-\mathrm{CH}=\underset{\alpha, \alpha^{\prime} \text { unsaturated }}{\mathrm{CH}-\mathrm{CH}_{2}-\mathrm{CH}}=\mathrm{CH}-$

There is a way to check the validity of $E_{3}$ values using the empirical equations by Korcek et al. (1972). These authors reported $\mathrm{C}-\mathrm{H}$ bond dissociation enthalpy (BDE) values for $\alpha$ and $\alpha, \alpha^{\prime}$ unsaturated methylene and a relationship linking this dissociation energy to $E_{3}$ :

$E_{3}=0.55 \times(\mathrm{BDE}(\mathrm{C}-\mathrm{H})-261)$

where $\mathrm{E}_{3}$ and $\mathrm{BDE}(\mathrm{C}-\mathrm{H})$ are expressed in $\mathrm{kJ} \mathrm{mol}^{-1}$.

$\mathrm{BDE}(\mathrm{C}-\mathrm{H})$ values and corresponding $E_{3}$ values for the less stable methylenes are in good agreement with theoretical expectations (Table 2) which is a first validation of Eq. (14). The significant gap between $E_{3}$ for a saturated substrate $\left(\sim 70 \mathrm{~kJ} \mathrm{~mol}^{-1}\right)$ and those for unsaturated substrates explains why oxidation is selective in the conditions under study and why only allylic hydrogens are attacked. However, let us precise that in ML and MLN, a cooxidation involving $m_{1}$ and $m_{2}$ sites (Table 1 ) possibly occurs and the model based on unicity of reactive site used here is only a rough approximation.

In the following, we will use the $E_{3}$ value coming from Korcek's relationship rather than the one determined from CL because there is no reason that ML and MLN reactivity differs. Concerning $k_{3}$, we will use another Korcek's relationship:

$\log _{10}^{\mathrm{s}-\mathrm{ROO}^{\circ}} k_{3}\left(30{ }^{\circ} \mathrm{C}\right)=16.4-0.0478 \times \mathrm{BDE}(\mathrm{C}-\mathrm{H})$

So that, using Eqs. (15) and (16):

$\log _{10}^{\text {S-ROO }}{ }^{\circ} k_{3}\left(30{ }^{\circ} \mathrm{C}\right)=3.9-0.0867 \times E_{3}$

$k_{3}$ at $30^{\circ} \mathrm{C}$ values are also listed in Table 2 . Having now $k_{3}\left(30^{\circ} \mathrm{C}\right)$, $E_{3}$, and then $k_{3}$ whatever the temperature, it remains to determine the kinetic parameters linked to initiation and termination. As illustrated elsewhere (Audouin et al., 1995; Richaud et al., 2006), kinetic parameters for initiation can be estimated from induction period duration.

\subsection{Identification of the couples $\left(k_{1 b 0}, E_{1 b}\right)$}

The analytical approach of the standard kinetic scheme gives (Audouin et al., 1995):

$t_{\mathrm{i}} \sim \frac{\ln \left(\left([\mathrm{ROOH}]_{\mathrm{S}}-[\mathrm{ROOH}]_{0}\right) /[\mathrm{ROOH}]\right)}{k_{3} \sqrt{\left(k_{1 \mathrm{~b}} / k_{6}\right)}[\mathrm{RH}]}$

where $[\mathrm{ROOH}]_{0}$ and $[\mathrm{ROOH}]_{S}$ are respectively the hydroperoxide concentrations at $t=0$ and at steady state, respectively. $[\mathrm{ROOH}]_{S}$ is a function of rate constants (Eq. (8)). $k_{1 \mathrm{~b}}$ can be calculated from $t_{\mathrm{i}}$ if $[\mathrm{ROOH}]_{0}$ and $k_{6}$ are fixed. It is easy to verify that $E_{1 \mathrm{~b}}$ and $k_{1 \mathrm{~b} 0}$ assessment from induction period values moderately depends on $[\mathrm{ROOH}]_{0}$ (Audouin et al., 1995). Several sets of $k_{60}$ and $E_{6}$ can be used for determining $k_{1 \mathrm{~b}}$ at the several temperatures under investigation (see Table 3 for some examples). The best $k_{1 \mathrm{~b} 0}, E_{1 \mathrm{~b}}$ pair and the $k_{60}, E_{6}$ pair from which it originates have to fulfill two conditions:

(1) Permit the simulation of the CL shape. As it will be seen in the following (Fig. 3b), experimental CL curves cannot be fairly simulated using $k_{6} \sim 10^{6} \mathrm{~L} \mathrm{~mol}^{-1} \mathrm{~s}^{-1}$ meanwhile $k_{6} \sim 10^{8} \mathrm{~L} \mathrm{~mol}^{-1} \mathrm{~s}^{-1}$ is more suitable.

(2) Have a physical sense. It can be tentatively justified by placing $k_{1 \mathrm{~b} 0}, E_{1 \mathrm{~b}}$ pairs for MO, ML and MLN together with comparable data obtained for several hydrocarbons (Broska et al., 1999) in the compensation diagram $\ln$ (pre exponential factor) vs activation energy (Fig. 2). Except for the ML, the points are reasonably close to a straight-line consistently with the fact that all these data correspond to the bimolecular decomposition of $\mathrm{ROOH}$.

Finally, the $k_{1 \mathrm{~b}}$ values obtained with $k_{6}\left(150^{\circ} \mathrm{C}\right)=10^{8} \mathrm{~L} \mathrm{~mol}^{-1} \mathrm{~s}^{-1}$ (with $E_{6}=0$ or $30 \mathrm{~kJ} \mathrm{~mol}^{-1}$ ) are very close and meet both requirements. They will be used in the next part with $k_{3}$ determined in Section 3 for simulating CL curves and identifying precisely the other parameters $\left(k_{6}\right.$ and $\left.[\mathrm{ROOH}]_{0}\right)$.

\subsection{Simulation of $C L$ curves and $[\mathrm{POOH}]_{0}$ and $\left(k_{60}, E_{6}\right)$ assessment}

The aim is now to assess $[\mathrm{POOH}]_{0}$ and $\left(k_{60}, E_{6}\right)$ from fitting CL curves or at least reproduce fairly their shape. To take into account the final auto-retardation, we added an equation for substrate consumption (Richaud et al., 2007):

$\frac{d[\mathrm{RH}]}{d t}=-\gamma_{1 \mathrm{~b}} k_{1 \mathrm{~b}}[\mathrm{ROOH}]^{2}-k_{3}\left[\mathrm{ROO}^{\circ}\right][\mathrm{RH}]$

where $\gamma_{1 b}$ is the number of substrate units consumed in the initiation process. For the sake of simplicity, we will assume that $\gamma_{1 b}=0$ (i.e. that carbonyls are the main products for alkoxy decomposition).

The complexity of differential system made of Eqs. (5)-(7) and (19) requires the use of a numerical solver: ODE23's function (Matlab software). The above system of equations can be solved using the following boundary conditions (Richaud et al., 2008):

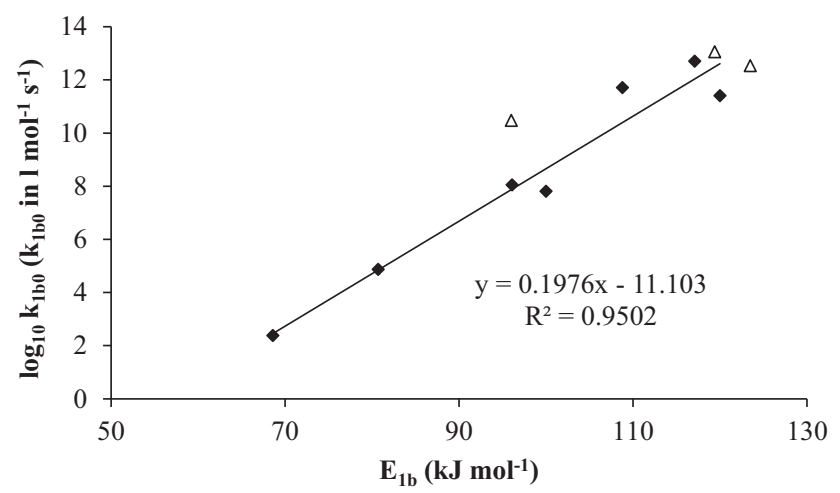

Fig. 2. Compensation straightline for Arrhenius parameters of bimolecular branching (data in full symbol from Broska et al., 1999) and in open symbols from this work). 

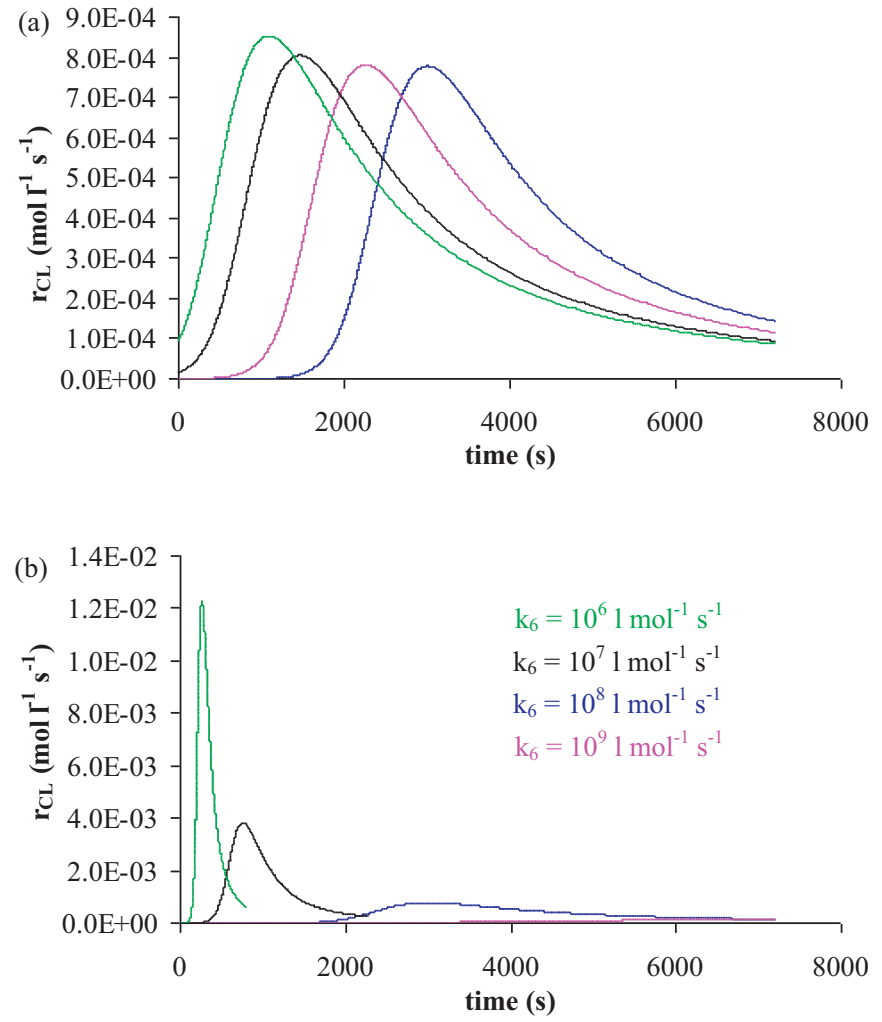

Fig. 3. Principle of adjustment of $[\mathrm{ROOH}]_{0}$ (a) and $k_{6}$ (b). Other parameters were fixed equal to: $\left[\mathrm{R}^{\circ}\right]=\left[\mathrm{ROO}^{\circ}\right]=0, \quad[\mathrm{RH}]=6 \mathrm{~mol} \mathrm{~L}^{-1}, \quad k_{1 \mathrm{~b}}=1 \times 10^{-2} \mathrm{~L} \mathrm{~mol}^{-1} \mathrm{~s}^{-1}$, $k_{2}=10^{7} \mathrm{~L} \mathrm{~mol}^{-1} \mathrm{~s}^{-1}$ and $k_{3}=100 \mathrm{~L} \mathrm{~mol}^{-1} \mathrm{~s}^{-1}, \quad k_{6}=10^{9} \mathrm{Lmol}^{-1} \mathrm{~s}^{-1}$ (a) and $[\mathrm{ROOH}]_{0}=10^{-2} \mathrm{~mol} \mathrm{~L}^{-1}$ (b).
Table 4

Chemiluminescence yield $\Phi$, termination rate constant $k 6$ and ration $k 6 / \Phi$ for methyl oleate, linoleate and linolenate for the temperatures under study, extrapolation of $k_{6}$ at $30^{\circ} \mathrm{C}$ and comparison with some literature data $\left({ }^{*}\right.$ ) (Kamiya and Niki, 1978)

\begin{tabular}{rrllll}
\hline & $T\left({ }^{\circ} \mathrm{C}\right)$ & $k_{6}$ & $\Phi$ & $k_{6} / \Phi$ & $k_{6}{ }^{*}$ \\
\hline O & 150 & $4.5 \times 10^{8}$ & $4.6 \times 10^{7}$ & 9.9 & \\
& 140 & $3.0 \times 10^{8}$ & $4.6 \times 10^{7}$ & 6.5 & \\
& 110 & $1.0 \times 10^{8}$ & $1.9 \times 10^{7}$ & 5.2 & \\
& 30 & $1.6 \times 10^{6}$ & & & \\
& & & & & \\
LO & 150 & $3.5 \times 10^{9}$ & $1.9 \times 10^{5}$ & $1.9 \times 10$ & \\
& 140 & $2.5 \times 10^{9}$ & $1.6 \times 10^{8}$ & $1.6 \times 10$ & \\
& 110 & $1.8 \times 10^{9}$ & $1.0 \times 10^{8}$ & $1.7 \times 10$ & \\
& 90 & $3.5 \times 10^{8}$ & $2.4 \times 10^{7}$ & $1.5 \times 10$ & \\
& 30 & $2.6 \times 10^{7}$ & & & \\
LNO & 150 & $3.5 \times 10^{9}$ & $1.4 \times 10^{8}$ & $2.4 \times 10$ & \\
& 135 & $1.7 \times 10^{9}$ & $6.7 \times 10^{7}$ & $2.4 \times 10$ & \\
& 110 & $8.0 \times 10^{8}$ & $6.6 \times 10^{7}$ & $1.2 \times 10$ & \\
& 30 & $1.38 \times 10^{7}$ & & & $1.8 \times 10^{7}$ \\
\hline
\end{tabular}

$I_{\mathrm{CL}} / I_{\mathrm{CLmax}}=f(t)$, i.e. it does not depend of CL yield $\Phi$. This latter is then adjusted from the following equation:

$\Phi=\frac{I_{\mathrm{CLmax}}}{k_{1 \mathrm{~b}}[\mathrm{POOH}]_{\max }^{2}}$

$[\mathrm{ROOH}]_{0}$ values are given in Table 2 and values of $k_{6}$ and $\Phi$ and the ratio $k_{6} / \Phi$ are listed in Table 4 . [ROOH $]_{0}$ of the 3 methyl esters under study have the same order of magnitude than reported in Kron et al.(1996). The corresponding activation energies are in good agreement with literature (Denisov and Afanas'ev, 2005b) and the extrapolated values of $k_{6}$ at $30^{\circ} \mathrm{C}$ are close to the ones reported by Kamiya and Niki (1978) and Tavadyan et al. (2007).

Att $=0$

$$
\begin{aligned}
& {\left[\mathrm{R}^{\circ}\right]=\left[\mathrm{ROO}^{\circ}\right]=0,} \\
& {[\mathrm{ROOH}]=[\mathrm{ROOH}]_{0}}
\end{aligned}
$$$$
[\mathrm{RH}]=[\mathrm{RH}]_{0} \quad(\text { see Table } 1)
$$

$\left[\mathrm{O}_{2}\right]=\mathrm{S}_{\mathrm{O}_{2}} \times \mathrm{P}_{\mathrm{O}_{2}}$ (Henry's law) with $\mathrm{S}_{\mathrm{O}_{2}}=4 \times 10^{-8} \mathrm{~mol} \mathrm{~L}^{-1} \mathrm{~Pa}^{-1} \quad$ (Van Krevelen and Te Nijenhuis, 2009)

(Van Krevelen and Te Nijenhuis, 2009).

And the following hypotheses:

(1) When two kinds of abstractable hydrogen coexist, only the most labile one reacts.

(2) Corresponding $k_{3}$ values are given in Table $2 . k_{2}$ was arbitrarily fixed equal to $10^{7} \mathrm{~L} \mathrm{~mol}^{-1} \mathrm{~s}^{-1}$ (Verdu and Verdu, 1997). Let us precise that $k_{2}$ value has a negligible influence on simulated oxidation curves provided its value is physically reasonable.

The other kinetic parameters were determined as follows:

- $k_{1 \mathrm{~b}}$ was determined from induction period values exploited using Eq. (13) (Table 3). We have chosen the values corresponding to $k_{6}\left(150^{\circ} \mathrm{C}\right)=10^{8} \mathrm{~L} \mathrm{~mol}^{-1} \mathrm{~s}^{-1}$ and $E_{6}=0$ having in mind that they are very close to those obtained with $k_{6}\left(150^{\circ} \mathrm{C}\right)=10^{8} \mathrm{~L} \mathrm{~mol}^{-1} \mathrm{~s}^{-1}$ and $E_{6}=30 \mathrm{~kJ} \mathrm{~mol}^{-1}$.

- The initial hydroperoxide concentration $[\mathrm{ROOH}]_{0}$ influences only induction period and will hence be determine from fitting of the beginning of the curve (Fig. 3a).

- $k_{6}$ is adjusted on the shape of the curve and in particular the maximal slope (Fig. 3b).

Let us precise that $k_{6}$ and $[\mathrm{ROOH}]_{0}$ adjustment is independent. It is the same in CL kinetic curves and in their reduced homologs
Let us first mention that despite its relative simplicity compared to previously published works (Tavadyan et al., 2007), the proposed model simulates the shape of CL curves with only 5 parameters ([ROOH $]_{0}, k_{\mathrm{b}}, k_{2}, k_{3}$ and $\left.k_{6}\right)$. The curve of $\mathrm{ROOH}$ build up has also the same shape than reported in literature (Raveh et al., 2001). In other words, the ignored reactions play a negligible kinetic role.

The obtained values of kinetic parameters call for the following comments:

- ML and MLN have close $k_{6}$ values and differ significantly from oleate in good agreement with the difference of reactivity of $\alpha$ unsaturated and $\alpha, \alpha^{\prime}$ unsaturated sites.

- The condition on substrate oxidizability: $k_{3}^{2} / k_{6}(\mathrm{MO})<k_{3}{ }^{2} / k_{6}(\mathrm{ML})$ and $k_{3}{ }^{2} / k_{6}(\mathrm{ML})=k_{3}{ }^{2} / k_{6}(\mathrm{MLN})$ seems also reasonable.

- $k_{6} / \Phi$ tends to increase with the number of unsaturation in the order MLN $>\mathrm{ML} \gg \mathrm{MO}$ (Table 4). It is almost constant with temperature for a given substrate. In other words, the Eq. (14) is a posteriori validated.

- Assuming a relative error ca. $5 \%$ on CL intensity, an uncertainty calculation shows that $\Delta k_{3} / k_{3} \sim 15 \%$ and $\Delta k_{6} / k_{6} \sim 30 \%$. Fig. $3 \mathrm{~b}$ shows for example that even $50 \%$ relative error on $k_{6}$ is not significant in the frame of such a coarse grain study. Rate constants are actually estimated by their order of magnitude rather than by the decimal value of pre-exponential factor. 


\section{Conclusions}

Thermal oxidation of fatty acids by products was studied by chemiluminescence at several temperatures. It appears that linoleate and linolenate behave similarly but differ from oleate. This result is consistent to the fact that the reactive sites of linoleate and linolenate ( $\alpha, \alpha^{\prime}$ unsaturated) are similar but differ from oleate ones ( $\alpha$ unsaturated).

A relatively simple model permitted to fit the CL curves for the three methyl esters under study in the $90-150{ }^{\circ} \mathrm{C}$ temperature range. Kinetic analysis allowed assessing the rate constants for simulating oxidation of methyl oleate, methyl linoleate and methyl linolenate and their respective activation energy. Proposed rate constants are in good agreement with literature data and available structure-reactivity relationships.

\section{Acknowledgments}

This work has been accomplished in the frame of the contract "BioCarbMat" and sponsored by the Competitivity Pole MOV'EO which is gratefully acknowledged.

\section{References}

Achimsky, L., Audouin, L., Verdu, J., Rychlá, L., Rychlý, J., 1999. The effect of oxygen pressure on the rate of polypropylene oxidation determined by chemiluminescence. European Polymer Journal 35, 557-563.

Audouin, L., Gueguen, V., Tcharkhtchi, A., Verdu, J., 1995. 'Close loop' mechanistic schemes for hydrocarbon polymer oxidation. Journal of Polymer Science Part A: Polymer Chemistry 33, 921-927.

Audouin-Jirackova, L., Verdu, J., 1987. Chemiluminescence of hydrocarbon polymers. Journal of Polymer Science Part A: Polymer Chemistry 25, 1205-1215.

Berdeaux, O., Fontagné, S., Sémon, E., Velasco, J., Sébédio, J.L., Dobarganes, C., 2012. A detailed identification study on high-temperature degradation products of oleic and linoleic acid methyl esters by GC-MS and GC-FTIR. Chem. Phys. Lipids 165, $338-347$.

Billingham, C., Grigg, M.N., 2004. The kinetic order of decomposition of polymer hydroperoxides assessed by chemiluminescence. Polymer Degradation and Stability 83, 441-451.

Broska, R., Rychly, J., Csomorova, K., 1999. Carboxylic acid assisted oxidation of polypropylene studied by chemiluminescence. Polymer Degradation and Stability 63, 231-236.

Colakoglu, A.S., 2007. Oxidation kinetics of soybean oil in the presence of monoolein, stearic acid and iron. Food Chemistry 101, 724-728.

Colin, X., Richaud, E., Verdu, J., Monchy-Leroy, C., 2010. Kinetic modelling of radiochemical ageing of ethylene-propylene copolymers. Radiation Physics and Chemistry 79, 365-370.

Coquillat, M., Verdu, J., Colin, X., Audouin, L., Nevière, R., 2007. Thermal oxidation of polybutadiene. Part 2. Mechanistic and kinetic schemes for additive-free noncrosslinked polybutadiene. Polymer Degradation and Stability 92, 1334-1342.

Cubillos, M.A., Lissi, E.A., Abuin, E.B., 2000. Kinetics of lipid peroxidation in compartmentalized systems initiated by a water-soluble free radical source. Chemistry and Physics of Lipids 104, 49-56.

Denisov, E.T., Afanas'ev, I.B., 2005a. Oxidation and Antioxidants in Organic Chemistry and Biology. CBC Taylor \& Francis Group, Boca Raton/London/New York/Singapore, pp. 137-184

Denisov, E.T., Afanas'ev, I.B., 2005b. Oxidation and Antioxidants in Organic Chemistry and Biology. CBC Taylor \& Francis Group, Boca Raton/London/New York/Singapore, pp. 23-83.

Fuchs, B., Bresler, K., Schiller, J., 2011. Oxidative changes of lipids monitored by MALDI MS. Chemistry and Physics of Lipids 164, 782-795.

Harada, Y., Suzuki, K., Hashimoto, M., Tsukagoshi, K., Kimoto, H., 2009. Chemiluminescence from singlet oxygen that was detected at two wavelengths and effects of biomolecules on it. Talanta 77, 1223-1227.

Hasegawa, H., Suzuki, K., Nakaji, S., Sugawara, K., 1997. Analysis and assessment of the capacity of neutrophils to produce reactive oxygen species in a 96-well microplate format using lucigenin- and luminol-dependent chemiluminescence. Journal of Immunological Methods 210, 1-10.

Herbinet, O., Pitz, W.J., Westbrook, C.K., 2008. Detailed chemical kinetic oxidation mechanism for a biodiesel surrogate. Combustion and Flame 154, 507-528.

Herbinet, O., Pitz, W.J., Westbrook, C.K., 2010. Detailed chemical kinetic mechanism for the oxidation of biodiesel fuels blend surrogate. Combustion and Flame 157, 893-908.
Kamiya, Y., Niki, E., 1978. Oxidative degradation. In: Jellinek, H.H.G. (Ed.), Aspects of Degradation and Stabilization of Polymers. Elsevier Applied Science Publishers, Barking, pp. 79-149.

Khelidj, N., Colin, X., Audouin, L., Verdu, J., Monchy-Leroy, C., Prunier, V., 2006. Oxidation of polyethylene under irradiation at low temperature and low dose rate Part II. Low temperature thermal oxidation. Polymer Degradation and Stability $91,1598-1605$

Korcek, S., Chenier, J.B.H., Howard, J.A., Ingold, K.U., 1972. Absolute rate constants for hydrocarbon auto-oxidation-activation energies for propagation and the correlation of propagation rate constants. Canadian Journal of Chemistry 50 2285-2297.

Kron, A., Stenberg, B., Reitberger, T., Billingham, N.C., 1996. Chemiluminescence from oxidation of polypropylene: correlation with peroxide concentration. Polymer Degradation and Stability 53, 119-127.

Matisová-Rychlá, L., Rychlý, J., Slovák, K., 2003. Effect of the polymer type and experimental parameters on chemiluminescence curves of selected materials. Polymer Degradation and Stability 82, 173-180.

Pajunen, T.I., Koskela, H., Hase, T., Hopia, A., 2008. NMR properties of conjugated linoleic acid (CLA) methyl ester hydroperoxides. Chemistry and Physics of Lipids $154,105-114$

Parejo, I., Petrakis, C., Kefalas, P., 2000. A transition metal enhanced luminol chemiluminescence in the presence of a chelator. Journal of Pharmacological and Toxicological Methods 43, 183-190.

Raveh, O., Pinchuk, I., Fainaru, M., Lichtenberg, D., 2001. Kinetics of lipid peroxidation in mixtures of HDL and LDL, mutual effects. Free Radical Biology and Medicine $31,1486-1497$.

Rhayem, Y., Thérond, P., Camont, L., Couturier, M., Beaudeux, J.-L., Legrand, A., Jore, D., Gardés-Albert, M., Bonnefont-Rousselot, D., 2008. Chain-breaking activity of resveratrol and piceatannol in a linoleate micellar model. Chemistry and Physics of Lipids $155,48-56$.

Richaud, E., Farcas, F., Bartoloméo, P., Fayolle, B., Audouin, L., Verdu, J., 2006. Effect of oxygen pressure on the oxidation kinetics of unstabilised polypropylene. Polymer Degradation and Stability 91, 398-405.

Richaud, E., Farcas, F., Fayolle, B., Audouin, L., Verdu, J., 2007. Hydroperoxide build-up in the thermal oxidation of polypropylene-a kinetic study. Polymer Degradation and Stability 92, 118-124.

Richaud, E., Colin, X., Fayolle, B., Audouin, L., Verdu, J., 2008. Induction period in the low-temperature thermal oxidation of saturated hydrocarbons: example of polyethylene. International Journal of Chemical Kinetics 40, 769-777.

Roginsky, V., 2010. Oxidizability of cardiac cardiolipin in Triton X-100 micelles as determined by using a Clark electrode. Chemistry and Physics of Lipids 163 , 127-130.

Schippling, S., Kontush, A., Arlt, S., Buhmann, C., Stürenburg, H.-J., Mann, U., MüllerThomsen, T., Beisiegel, U., 2000. Increased lipoprotein oxidation in Alzheimer's disease. Free Radical Biology and Medicine 28, 351-360.

Schnitzer, E., Pinchuk, I., Bor, A., Fainaru, M., Samuni, A.M., Lichtenberg, D., 1998 Lipid oxidation in unfractionated serum and plasma. Chemistry and Physics of Lipids 92, 151-170.

Spiteller, G., 1998. Linoleic acid peroxidation-the dominant lipid peroxidation process in low density lipoprotein-and its relationship to chronic diseases. Chemistry and Physics of Lipids 95, 105-162.

Tavadyan, L., Khachoyan, A., Martoyan, G., Kamal-Eldin, A., 2007. Numerical revelation of the kinetic significance of individual steps in the reaction mechanism of methyl linoleate peroxidation inhibited by $\alpha$-tocopherol. Chemistry and Physics of Lipids 147, 30-45.

Tobolsky, A.V., Metz, D.J., Mesrobian, R.M., 1950. Low temperature autoxidation of hydrocarbons: the phenomenon of maximum rates. Journal of the American Chemical Society 72, 1942-1952.

Tükenmez, İ., Sitki Ersen, M., Bakioğlu, A.T., Biçer, A., Pamuk, V., 1997. Dose dependent oxidation kinetics of lipids in fish during irradiation processing. Radiation Physics and Chemistry 50, 407-414.

Van Krevelen, D.W., Te Nijenhuis, K., 2009. Properties of Polymers, their Correlation with Chemical Structure; their Numerical Estimation and Prediction from Additive Group Contributions, 4th ed. Elsevier, Amsterdam, pp. 655-702.

Verdu, S., Verdu, J., 1997. A new kinetic model for polypropylene thermal oxidation at moderate temperatures. Macromolecules 30, 2262-2267.

Youdim, K.A., Martin, A., Joseph, J.A., 2000. Essential fatty acids and the brain: possible health implications. International Journal of Developmental Neuroscience 18, 383-399.

Zhou, B., Yang, L., Liu, Z.-L., 2004. Strictinin as an efficient antioxidant in lipid peroxidation. Chemistry and Physics of Lipids 131, 15-25.

\section{Glossary}

$B D E$ : bond dissociation energy

$C L$ : chemiluminescence

$M L$ : methyl linoleate

MLN: methyl linolenate

MO: methyl oleate

UFE: unsaturated fatty esters 